\title{
A rare case of coexisting left pulmonary hypoplasia and right tracheal bronchus
}

\author{
Hameed Aboobackar Shahul, Mohan K Manu, Aswini Kumar Mohapatra
}

Department of Pulmonary Medicine, Kasturba Medical College Manipal, Manipal University, Manipal, Karnataka, India

\section{Correspondence to} Dr Mohan K Manu, manumohan73@gmail.com

Accepted 7 August 2014
CrossMark

To cite: Shahul HA Manu MK, Mohapatra AK. BMJ Case Rep Published online: [please include Day Month Year] doi:10.1136/ bcr-2014-205008

\section{DESCRIPTION}

A 23-year-old woman presented with a 10-year history of recurrent breathlessness and cough. Her medical history was unremarkable except for asthma, which was under control. General physical examination was normal. A respiratory system examination revealed mediastinal shift to left with features of volume loss of the left hemithorax. Breath sounds were reduced and a dull percussion note was present over the left basal areas.

Routine blood investigations were normal. Chest radiograph (figure 1) revealed mediastinal shift to left with volume loss of the left hemithorax and elevated left hemidiaphragm. Sputum Ziehl-Neelsen staining for mycobacteria and bacterial culture were negative. Contrast-enhanced CT (CECT) of the thorax revealed a right displaced tracheal bronchus (figure 2A), a left pulmonary arterial tree with small branches (figure $2 \mathrm{~B}$ ), a left bronchial tree with reduced calibre (figure 2C), reduced volume of left lung and mediastinal shift to left. The right lung was hyperinflated and herniating to the opposite side (figure 2D). The threedimensional image reconstruct (figure 3A, B) clearly demarcated the above findings. CT features

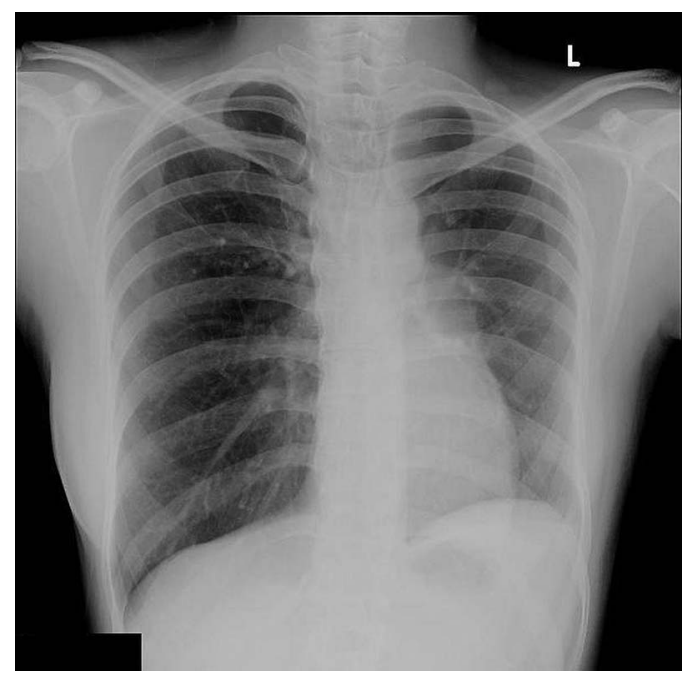

Figure 1 Chest radiograph (posteroanterior view) showing mediastinal shift to left with volume loss of the left hemithorax and elevated left hemidiaphragm.

were consistent with left pulmonary hypoplasia and a coexisting right tracheal bronchus. Abdominal and pelvic sonography, ECG and echocardiogram were normal. The patient was managed

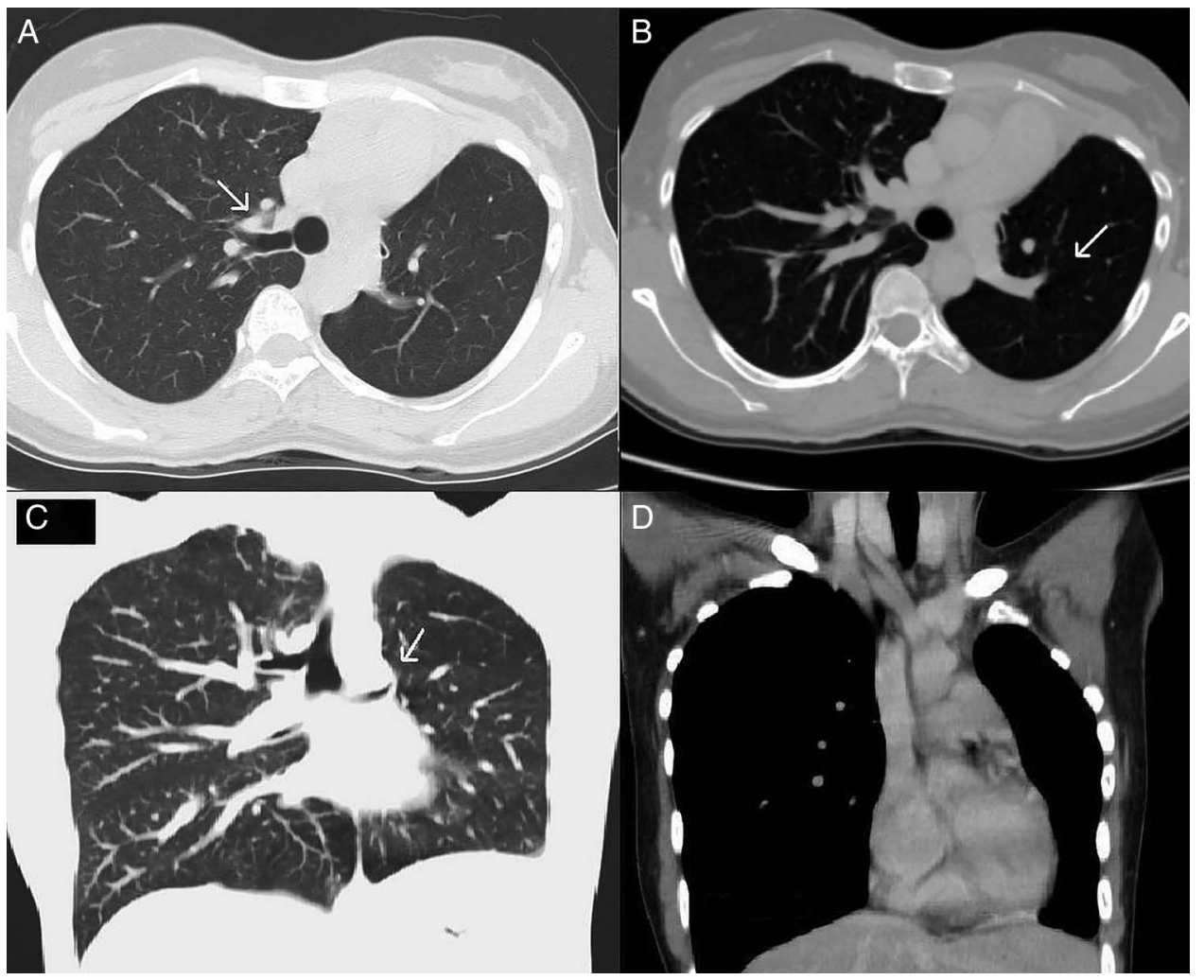

Figure 2 Contrast-enhanced CT of the thorax showing a right displaced tracheal bronchus ( $A$; white arrow), a left pulmonary arterial tree with small branches $(B$; white arrow), a left bronchial tree with reduced calibre $(C ;$ white arrow), reduced volume of left lung and mediastinal shift to left. The right lung is hyperinflated and herniating to the opposite side (D). 


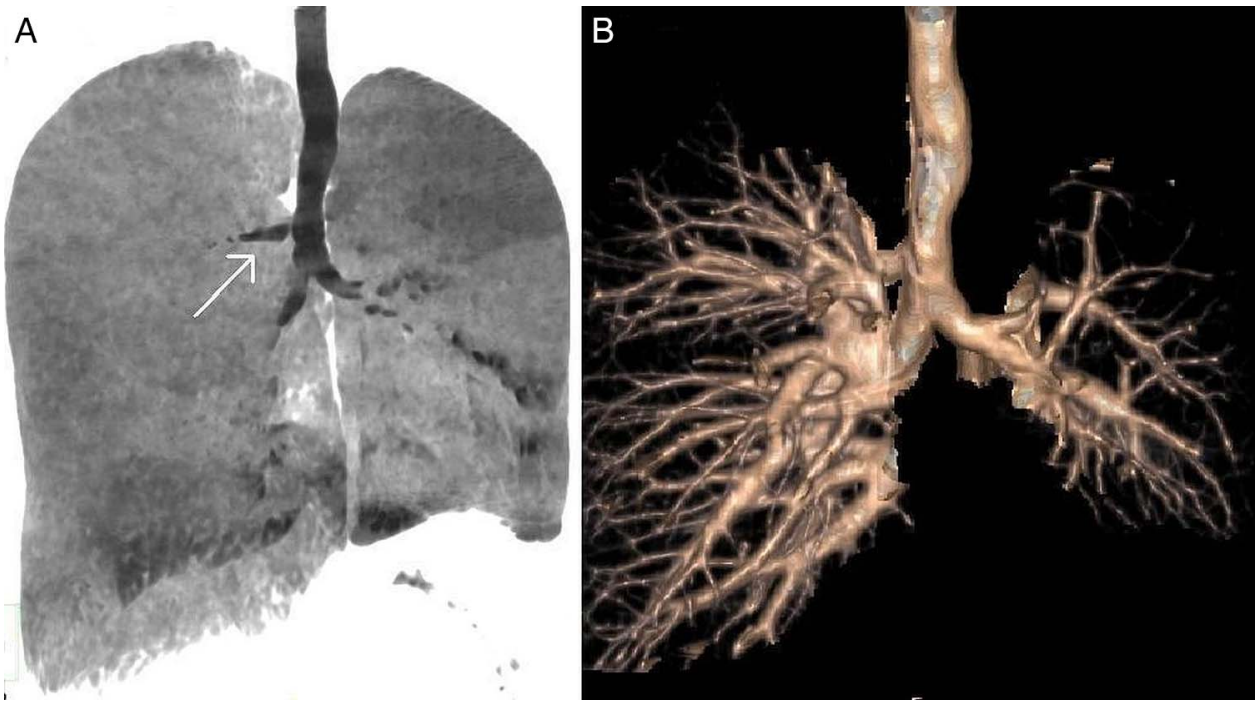

Figure 3 Three-dimensional image reconstruct showing a right displaced tracheal bronchus ( ; white arrow) and underdeveloped left-sided bronchial tree with decreased calibre and reduced number of branching airways (B).

symptomatically with inhalational bronchodilators and expectorants. She was advised to continue medications for asthma and was advised regular follow-up in view of possible infections and complications.

\section{Learning points}

- A variety of conditions such as atelectasis and fibrothorax can present on chest radiograph as ipsilateral volume loss, pulmonary hypoplasia being an important differential.

- The knowledge of tracheal anomalies, including tracheal bronchus, is important and has application in emergency procedures such as endotracheal intubation.

- Pulmonary hypoplasia and tracheal bronchus are two congenital anomalies that can be diagnosed on CT of the thorax. The coexistence of the two conditions in the same person is very rare.
Pulmonary hypoplasia refers to a congenital maldevelopment in which all normal pulmonary tissues are present but are underdeveloped. ${ }^{1}$ It is much rarer on the left side in comparison to the right. Pulmonary hypoplasia is associated with other congenital anomalies such as cardiovascular defects, bronchogenic cysts, diaphragmatic hernias and skeletal anomalies. Tracheal bronchus refers to bronchial anomalies arising in the trachea or main bronchus and directed towards the upper lobe. ${ }^{2}$ The coexistence of pulmonary hypoplasia and tracheal bronchus in the same person is extremely rare and is seldom reported.

Competing interests None.

Patient consent Obtained.

Provenance and peer review Not commissioned; externally peer reviewed.

\section{REFERENCES}

1 Sadler TW. Respiratory system. In: Sadler TW ed, Langman's medical embryology. 8th edn. Lippincott Williams \& Wilkins, 2009:275-84.

2 Berrocal T, Madrid C, Novo S, et al. Congenital anomalies of the tracheobronchial tree, lung, and mediastinum: embryology, radiology, and pathology. Radiographics 2003;24:e17.

Copyright 2014 BMJ Publishing Group. All rights reserved. For permission to reuse any of this content visit http://group.bmj.com/group/rights-licensing/permissions.

BMJ Case Report Fellows may re-use this article for personal use and teaching without any further permission.

Become a Fellow of BMJ Case Reports today and you can:

- Submit as many cases as you like

- Enjoy fast sympathetic peer review and rapid publication of accepted articles

- Access all the published articles

- Re-use any of the published material for personal use and teaching without further permission

For information on Institutional Fellowships contact consortiasales@bmjgroup.com

Visit casereports.bmj.com for more articles like this and to become a Fellow 